\title{
Aquatic Therapy for a Patient with Postural Orthostatic Tachycardia Syndrome: a Case Report
}

Christine Tito

Midwestern University, Downers Grove, cblasdel52@midwestern.edu

Judith Burton Hess

Midwestern University - Downers Grove, jhessx@midwestern.edu

Follow this and additional works at: https://nsuworks.nova.edu/ijahsp

Part of the Physical Therapy Commons

\section{Recommended Citation}

Tito C, Hess JB. Aquatic Therapy for a Patient with Postural Orthostatic Tachycardia Syndrome: a Case Report. The Internet Journal of Allied Health Sciences and Practice. 2017 Jan 01;15(3), Article 10.

This Manuscript is brought to you for free and open access by the College of Health Care Sciences at NSUWorks. It has been accepted for inclusion in Internet Journal of Allied Health Sciences and Practice by an authorized editor of NSUWorks. For more information, please contact nsuworks@nova.edu. 


\title{
Aquatic Therapy for a Patient with Postural Orthostatic Tachycardia Syndrome: a Case Report
}

\begin{abstract}
Background and Purpose: Postural Orthostatic Tachycardia Syndrome (POTS) can have a debilitating effect on an individual's quality of life. The purpose of this case report is to describe the use of interval training in an aquatic environment to decrease the symptoms of Postural Orthostatic Tachycardia Syndrome. Aquatic therapy provides benefits for individuals with cardiovascular issues, mainly through the principle of hydrostatic pressure. Hydrostatic pressure aids in shunting the blood from the extremities back to the heart, thus increasing cardiac output while reducing the individual's heart rate. Description: An 18 year-old female high school student who had been experiencing Postural Orthostatic Tachycardia Syndrome symptoms for approximately one year. These symptoms prevented her from participating in school or recreational activities. Intervention: The patient underwent 11 sessions of an aquatic interval program. Her subjective report, heart rate, blood pressure, and rate of perceived exertion were monitored throughout each session. Outcomes: After completing physical therapy, the patient had attained all of her functional goals including standing for 45 minutes, walking between classes at school, and attending her prom. The patient reported that she had not had a fainting spell in over 4 weeks. Despite these functional gains, the patient's Quality of Life score, as measured by the World Health Organization Quality of Life-BREF questionnaire (a condensed version of the original World Health Organization Quality of Life-100), declined in the following categories: physical health, psychological health, and environment. Discussion: The patient's exercise-specific heart rate and rate of perceived exertion decreased as sessions progressed, demonstrating an increased activity tolerance. It is hypothesized that the positive effects of hydrostatic pressure on the cardiovascular system contributed to the improvement in exercise tolerance and ultimately to her overall conditioning and activity tolerance. The results of this case report suggest that aquatic therapy may be an appropriate exercise modality for patients with Postural Orthostatic Tachycardia Syndrome. Continued research on the effects of aquatic therapy on the symptoms of Postural Orthostatic Tachycardia Syndrome is warranted.
\end{abstract}

\section{Author Bio(s)}

Christine Tito, PT, DPT is a Staff Physical Therapist at Athletico Physical Therapy in Plainfield, IL.

Judith Burton Hess, PT, DHS, OCS, Cert. DN is an Assistant Professor of Physical Therapy at Midwestern University in Downers Grove, IL. 


\title{
IUAHSP \\ The Internet Joưnal of Allied Health Sciences and Practice
}

Dedicated to allied health professional practice and education

Vol. 15 No. 3 ISSN 1540-580X

\section{Aquatic Therapy for a Patient with Postural Orthostatic Tachycardia Syndrome: a Case Report}

\author{
Christine Tito, PT, DPT \\ Judith Burton Hess, PT, DHS, OCS \\ Midwestern University \\ United States
}

\begin{abstract}
Background and Purpose: Postural orthostatic tachycardia syndrome (POTS) can have a debilitating effect on an individual's quality of life. The purpose of this case report is to describe the use of interval training in an aquatic environment to decrease the symptoms of POTS. Aquatic therapy provides benefits for individuals with cardiovascular issues, mainly through the principle of hydrostatic pressure. Hydrostatic pressure aids in shunting the blood from the extremities back to the heart, thus increasing cardiac output while reducing the individual's heart rate. Description: An 18 year-old female high school student who had been experiencing POTS symptoms for approximately one year. These symptoms prevented her from participating in school or recreational activities. Intervention: The patient underwent 11 sessions of an aquatic interval program. Her subjective report, heart rate, blood pressure, and rate of perceived exertion were monitored throughout each session. Outcomes: After completing physical therapy, the patient had attained all of her functional goals including standing for 45 minutes, walking between classes at school, and attending her prom. The patient reported that she had not had a fainting spell in over 4 weeks. Despite these functional gains, the patient's Quality of Life score, as measured by the World Health Organization Quality of Life-BREF questionnaire (a condensed version of the original World Health Organization Quality of Life-100), declined in the following categories: physical health, psychological health, and environment. Discussion: The patient's exercise-specific heart rate and rate of perceived exertion decreased as sessions progressed, demonstrating an increased activity tolerance. It is hypothesized that the positive effects of hydrostatic pressure on the cardiovascular system contributed to the improvement in exercise tolerance and ultimately to her overall conditioning and activity tolerance. The results of this case report suggest that aquatic therapy may be an appropriate exercise modality for patients with POTS. Continued research on the effects of aquatic therapy on the symptoms of POTS is warranted.
\end{abstract}

\section{INTRODUCTION}

\section{Postural Orthostatic Tachycardia Syndrome}

Postural orthostatic tachycardia syndrome (POTS) was first described in the 1940s but was not named and identified as its own syndrome until 1993. ${ }^{1}$ POTS has been described as an autonomic dysfunction that affects nearly 500,000 Americans. ${ }^{2}$ This condition affects the age group of 12 to 50 year olds but is more commonly found in adolescent females. ${ }^{3}$ Some of the symptoms described in the literature include but are not limited to light-headedness, fatigue, sweating, tremors, anxiety, palpitation, exercise intolerance, migraine headache, abdominal pain, muscle soreness, and fainting.1-11 Patients with POTS also present with increased incidence of depression and anxiety. Anderson et al demonstrated that when compared to a group of healthy individuals, patients with POTS scored significantly lower in all domains on the SF-36 quality of life questionnaire and demonstrated increased sensitivity to cognitive and cardiac symptoms, leading to an increase in anxiety. ${ }^{12}$ Thirteen of the fifteen patients with POTS, also presented with a mild to moderate depressive disorder. These symptoms greatly impact an individual's day-to-day activities and ultimately their quality of life (QOL). ${ }^{12}$ Benrud-Larson et al has shown that patients with POTS have a similar QOL to patients with chronic obstructive pulmonary disorder (COPD) and chronic heart failure (CHF). ${ }^{11}$ 
POTS is defined as an increase in heart rate of 30 beats per minute (bpm) upon standing or an increase of heart rate beyond $120 \mathrm{bpm}$ within the first 10 minutes of standing, not associated with other chronic conditions or medications known to diminish vascular or autonomic. 1-8,14,15 Recent studies recommend using a $40 \mathrm{bpm}$ increase in heart rate for adolescents. ${ }^{14,15}$ Criteria for the diagnosis of POTS require the following: symptoms that last at least 6 months, symptoms that worsen upon standing and improve with reclining or laying supine, and blood pressure and heart rate monitoring during a tilt table test $\left(70^{\circ}\right.$ for $45 \mathrm{~min}$ or until the subject faints). ${ }^{2-8,14,15} \mathrm{~A}$ positive tilt table test is indicated by an increase in heart rate of greater than $30 \mathrm{bpm}$, and the feeling of faintness or dizziness. Unlike other patients with orthostatic intolerance, patients with POTS may demonstrate little or no changes in blood pressure during the tilt table test. 13,16

The pathophysiology behind POTS is not yet fully understood. Individuals with POTS experience a dysregulation of their autonomic nervous system, which controls bodily functions such as sweating, heart rate, blood pressure, digestion, vascular tone, and temperature regulation. POTS may occur following prolonged bed rest after an infection or surgery. Multiple variations of POTS have been described in the literature, but there are two types that are most common. Neuropathic POTS is thought to be associated with peripheral neuropathy, and is characterized by anhydrosis of the legs and impaired vasoconstriction leading to pooling of blood in the lower extremities. $4,5,7,8$ Hyperadrenergic POTS is characterized by an increased firing of sympathetic nerve activity, with patients demonstrating augmented firing of cardiac sympathetic fibers, even in supine. $., 5,7,8$ Crnosija et al found that the response to the tilt test is distinctly different between patients with hyperadrenergic and non-hyperadrenergic POTS. ${ }^{16}$ Both groups of patients responded to the $70^{\circ}$ tilt position with increased $\mathrm{HR}$ and systolic blood pressure (sBP), but only the non-hyperadrenergic patient demonstrated at drop in diastolic blood pressure (dBP). ${ }^{16}$ Fu and Levine demonstrated that patients with POTS had an excessive increase in heart rate and reduced stroke volume during acute exercise compare to healthy subjects, suggesting that the tachycardia in POTS is related to decreased stroke volume rather than an abnormality of heart rate regulation. ${ }^{17}$

Increasing evidence suggests that physical deconditioning is an important contributor to POTS symptoms, proving a rationale for physical activity as an intervention strategy for POTS. ${ }^{16}$ There are few published studies that describe physical therapy interventions for individuals with POTS. Crnosija et al suggest light exercise until tolerance to positional changes is improved. ${ }^{16}$ However, none of these articles have discussed specific physical therapy interventions. ${ }^{16}$ After completion of a progressive 3month exercise program, patients with POTS demonstrated increased stroke volume and cardiac output, with a lower heart rate at any give $\mathrm{VO}_{2}$ during exercise. Additionally, they reported increases in left ventricular mass (12\%), end-diastolic volume (8\%), and blood volume (6\%) upon completion of the study. ${ }^{16}$ Fifty-three percent (53\%) of the patients who completed the study no longer met the diagnostic criteria for POTS. The severity of the POTS symptoms was shown to be a major factor limiting exercise tolerance and response to training, as patients with moderate to severe symptoms were among the patients not "cured." Crnosija et al concluded that these patients may have needed a longer duration of the exercise program to normalize their exercise capacity. ${ }^{16}$

Common non-pharmacological interventions include water and salt supplementation and compression garments.3-6,8-11 Studies have shown that the ingestion of water stimulates a pressor response, for individuals with autonomic dysfunction and older adults, and can dramatically increase an individual's blood pressure depending on the volume of water consumed.9,10

Pharmacological treatments include but are not limited to mineral corticoids, midodrine, beta blockers, acetylcholinesterase inhibitors, vasoconstrictors, erythropoietin, and anti-depressants. ${ }^{3-6,8,11}$ Research on the effects of these medications on individuals with POTS has been conducted (with the exception of anti-depressants) and the results on the effectiveness of these medications are varied depending on the individuals' symptoms. Mineral corticoids act by promoting intravascular volume expansion, thus improving blood pressure; however, mineral corticoids can often cause headaches and migraines which are associated symptoms of POTS. ${ }^{4}$ Midodrine elicits peripheral vasoconstriction which decreases venous pooling, but can cause urinary retention in individuals with bladder disorders. ${ }^{4}$ Beta blockers control excessive sinus tachycardia but can also exacerbate fatigue, exercise intolerance, and hypotension. ${ }^{4}$ Acetylcholinesterase inhibitors prolong the effects of acetylcholinesterase which leads to sympathetic vasoconstrictor output; however, this medication can activate muscarinic receptors leading to increased gastrointestinal symptoms. ${ }^{4}$ Vasoconstrictors such as clonidine improve venous tone but can actually reduce an individual's blood volume, secondary to the actions of the sympathetic nervous symptoms, with long term use. ${ }^{6}$ Erythropoietin results in an increase in central blood volume but is expensive and must be administered subcutaneously. ${ }^{5}$ Anti-depressants (selective serotonin reuptake inhibitors (SSRIs) improve nerve conduction and improve the standing vasoconstrictor reflex which reduces venous pooling, but they also have numerous unpleasant side effects. ${ }^{3}$

\section{Aquatic Therapy}

Aquatic therapy (or exercising in water) has been found to be beneficial with range of motion exercises, initiate resistance training and weight bearing, facilitate cardiovascular exercises, and enhance patient relaxation. ${ }^{19}$ The physical properties of water

(C) The Internet Journal of Allied Health Sciences and Practice, 2017 
include buoyancy, hydrostatic pressure, viscosity, and surface tension. Of these properties, buoyancy and hydrostatic pressure are the properties that aid the most in rehabilitation. Buoyancy is the upward force that opposes gravity. In an aquatic environment, buoyancy partially unloads the individual's joints and provides resistance to movement. ${ }^{19}$ Notably, different modes of aquatic exercise will elicit different biomechanical and physiological responses. For example, deep water running does not include ground contact, so the absence of ground reaction forces may decrease energy expenditure required. Likewise, if the individual is stationary in the water, as in deep water exercise, there will be less energy expenditure due to viscosity and drag forces compared to shallow water exercise when the individual is moving through the water.

A systematic review by Denning et al compared physiologic responses to exercise during over-land exercise and various modes of aquatic exercise. ${ }^{20}$ Modes relevant to this case report included shallow water running, water calisthenics, and deep water running. Eleven studies compared maximum oxygen consumption $\left(\mathrm{VO}_{2 \max }\right)$ during deep water to over-land running in healthy individuals. All of the studies reported lower $\mathrm{VO}_{2 \max }$ (average $=18.5 \%$, range $=10$ to $27 \%$, median $18.5 \%$ ) with deep water running. Three studies compared shallow water running to over-ground running, with $\mathrm{VO}_{2 \max }$ decreased during shallow water running, but to a lesser extent than deep water running (10 to 16\%). Because heart rate is a component of cardiac output and hence, $\mathrm{VO}_{2}$, trends in the literature related to heart rate tend to follow $\mathrm{VO}_{2}$. Five studies compared oxygen consumption during water calisthenics to similar exercises on land, with greater $\mathrm{VO}_{2}$ values during water calisthenics in four of the five studies, although quantitative data was only provided for one study. ${ }^{20}$

The benefits of aquatic therapy on the cardiovascular system are primarily a result of hydrostatic pressure, or the pressure that the water places on objects that are immersed. ${ }^{21}$ The deeper the object, the greater the hydrostatic pressure. When an individual is immersed in water, hydrostatic pressure contributes to a higher amount of central blood volume because of an increased pressure on the peripheral blood vessels. ${ }^{21-23}$ The increased hydrostatic pressure contributes to a reduced heart rate, which helps the individual perform the same exercises they could do on land but with a lower rate of perceived exertion (RPE).21-23 Because of this effect the use of RPE is more effective than measuring heart rate during an aquatic therapy cardiovascular program..$^{21}$

Aquatic therapy also has a psychological impact because it allows individuals to perform activities that they may not be able to perform outside of the water. Exercise itself has been shown to increase psychological well-being, decrease anxiety and depression, increase memory and cognitive function, increase quality of sleep, and decrease mental decline. ${ }^{24}$ For those who cannot exercise on land, aquatic exercises can be used to capitalize on these benefits. Patients that may have difficulty exercising on land include those with painful conditions such as rheumatoid arthritis, osteoarthritis, or fibromyalgia, as well as cardiopulmonary issues, including left ventricular dysfunction, chronic obstructive pulmonary disease, or stable chronic heart failure..$^{25}$

Physical therapists must complete a thorough patient evaluation prior to starting any type of exercise program. Aquatic therapy is contraindicated for patients with, uncontrolled seizures, unstable angina, open wounds, active infections, bowel incontinence with diarrhea, fever, active skin infections, or deep vein thrombosis without anticoagulation therapy or a filter. Precautions to aquatic therapy include sensitivity to heat/humidity, sensitivity to disinfection chemicals, hydrophobia, compromised immune systems, poor cognition, orthostatic hypotension, or compromised hemodynamics. ${ }^{19,21}$

\section{Purpose}

The purpose of this case report is to introduce and discuss the use of interval training in an aquatic environment to decrease the symptoms of POTS.

\section{CASE DESCRIPTION}

\section{History}

The patient was an 18-year old female high school senior who presented to the physical therapy clinic, referred by a pediatric cardiologist, with a diagnosis of POTS. Written informed consent was obtained from the patient. She stated that her symptoms began following a strep throat infection approximately one year prior to her physical therapy evaluation. The following symptoms were reported over the past several months: dizziness, achy bones and joints, tunnel vision, migraine headaches, fatigue, shortness of breath, palpitations, nausea, and fainting spells. In the month prior to her physical therapy evaluation the patient had estimated that she had experienced approximately 15 fainting spells that occurred without any warning symptoms and resulted in the patient falling to the floor. Following these fainting episodes, she would experience migraine headaches, achy bones and joints, and fatigue that persisted for several days. No significant injuries were reported as a result of these falls. Prior to referral to physical therapy, medical tests ruled out other conditions causing tachycardia, including other causes of

(c) The Internet Journal of Allied Health Sciences and Practice, 2017 
tachycardia, endocrine abnormalities, adverse drug effects or interactions, kidney disease, and other causes of autonomic dysfunction. $7,8,13$

The patient was only able to stand for 10 to 15 minutes at a time before she would have a fainting episode. The severity of her symptoms limited the patient to a very sedentary lifestyle. The patient had missed multiple days of school as a result of her condition and when she attended school, she required a wheelchair to navigate the hallways. Current medications included Bystolic (cardio-selective beta blocker medication), Fluoracortisone (for fluid and salt retention) and Nuun tablets (an electrolyte supplement to replace sodium tablets). Additionally, she wore lower extremity compression garments $(40$ to $50 \mathrm{mmHg}$ ) to assist with blood flow. Prior to the onset of this condition, she participated in Irish dance, choir, and was the school mascot. Her past medical history included gallbladder surgery in 2011. The patient's goals for physical therapy included being able to 1) stand for 45 minutes at her upcoming choir concert, 2) walk independently at school to change classrooms and socialize with her friends, and 3 ) return to her previous recreational activities.

\section{Evaluation}

The patient presented to the clinic ambulating without an assistive device. Postural observation in standing revealed a forward head posture. Gross ROM of bilateral upper and lower extremities was within normal limits (WNL). The patient demonstrated manual muscle testing (MMT) grades of $5 / 5$ throughout bilateral upper and lower extremities except for $4 / 5$ bilateral hip extension and abduction. Manual muscle testing has been shown to have 82 to $97 \%$ inter-rater reliability, 96 to $98 \%$ test-retest reliability. ${ }^{26}$ The patient demonstrated poor strength in her abdominal muscles. A vertebral artery test performed to rule out any involvement of the vertebral artery was negative. Specific metrics on the vertebral artery supine with cervical extension, side bending, and rotation are not available and the usefulness of this test is inconclusive. ${ }^{27}$

Throughout the examination, the patient showed signs of exertion from positional changes, including increased pallor, shortness of breath, and clammy palms. Heart rate (HR) and blood pressure (BP) were assessed in supine (140/82 $\mathrm{mmHg})$, immediately upon assuming a sitting position, $(138 / 82 \mathrm{mmHg})$, and immediately after standing $(126 / 78 \mathrm{mmHg})$. There is currently no literature regarding the reliability and validity of assessing BP changes from supine to sit to stand when assessing orthostatic hypotension. ${ }^{28}$ The consensus definition of orthostatic hypotension requires a drop in systolic blood pressure (SBP) of at least $20 \mathrm{mmHg}$ or a drop in diastolic blood pressure (DBP) of at least $10 \mathrm{mmHg}$ within 3 minutes of standing, which was not observed in this case. ${ }^{29}$ However, from supine to sitting the patient's HR increased 10 beats per minute (bpm) to $78 \mathrm{bpm}$. Likewise, from sit to stand, her pulse increased an additional $30 \mathrm{bpm}$ to $108 \mathrm{bpm}$, with the patient reporting subjective complaints of dizziness.

The patient completed a 6-minute walk test (6MWT) to assess sub-maximal aerobic capacity and endurance. Prior to the 6MWT, the patient's HR was $100 \mathrm{bpm}$. At approximately 3 minutes the patient reported feelings of fatigue and exhibited shortness of breath but was able to complete the test. The patient walked 0.25 miles in 6 minutes and her HR upon completion of the 6MWT was $125 \mathrm{bpm}$. According to Geiger et al, the normal distance achieved during the 6MWT for 16 to 18 year old females is 0.382 to. 443 miles. ${ }^{30}$ The test-retest reliability of the 6MWT is excellent, with an ICC of .94-.96 in healthy and overweight children and adolescents. ${ }^{31-32}$

The patient also completed the brief version of the World Health Organization Quality of Life questionnaire (WHOQOL-BREF) (see Appendix A). ${ }^{33}$ The WHOQOL-BREF is a 26-item questionnaire focusing on the patient's quality of life, overall and in four domains: physical health, psychological health, social relationships, and environment. Items are rated on a 5 point-Likert scale to determine a raw score. These raw scores are then transformed into percentages so that they can be used to compare to other WHOQOL instruments (see Appendix A for scoring instructions). The higher the transformed score, the better the quality of life (QOL) of the subject. The patient's overall quality of life transformed score was $37.5 \%$, while domain quality of life scores were $42.9 \%$ for physical health, $45.8 \%$ for psychological, $25 \%$ for social relationships, and $96.4 \%$ for environment. (internal consistency reliability for adolescents .89$) .33$

\section{Interventions}

Over a 10-week period, the patient participated in 11 physical therapy sessions consisting of cardiovascular interval training in an aquatic environment with the water temperature between $80^{\circ} \mathrm{F}$ and $85^{\circ} \mathrm{F}$. Initially, the patient completed her exercises at a water depth of 3 feet 6 inches and progressed to a water depth of 5 feet with the use of an aqua jogger vest. Although the patient may have had greater cardiovascular benefits in deep water initially, shallow water exercises were introduced to assuage the patient's anxiety regarding exercising in the water. Given the frequency with which she had been experiencing fainting episodes, the patient was more comfortable in shallow water, close to the edge of the pool. The intensity of the exercises was modified to the patient's tolerance by adjusting the speed and excursion of the exercises. A typical exercise session included a warm up, 45 cardiopulmonary exercises (4 repetitions of each exercise with a break between each repetition), and a cool down. Initially the warm up consisted of water walking 25 yards forward, backward, and sideways, and progressed to a kickboard warm up of the

(c) The Internet Journal of Allied Health Sciences and Practice, 2017 
same distance. Each treatment session was followed with a similar cool down. Table 1 provides a summary of the exercise program, as well as the patient's subjective and physiological responses.

Interval training was initiated with 30-second bouts of each exercise repeated 4 times, with a 1-minute "rest" period between repetitions. The patient performed marching or side-stepping activities during the "rest" period. Over time, the duration of each exercise bout progressively increased to 1 minute while the rest period duration decreased to 30 seconds. After the completion of 4 repetitions of each exercise, the physical therapist recorded the patient's heart rate (using a portable pulse oximeter) and rate of perceived exertion (RPE) using the Borg Rate of Perceived Exertion 15 point scale. Pulse oximetry had been shown to be a reliable and valid tool for assessing heart rate. ${ }^{34}$ The Borg scale has a mean validity coefficients of 0.74 compared to heart rate, and 0.83 compared to blood lactate threshold. ${ }^{35}$ Each treatment session was followed with a similar cool down. Table 1 provides a summary of the exercise program, as well as the patient's subjective and physiological responses.

Table 1: Summary of Interventions and Pre- and Post-Exercise Vital Signs

\begin{tabular}{|c|c|c|c|c|c|c|}
\hline Date & Pre-Rx Vitals & Post-Rx Vitals & Exercises Completed & $\mathrm{HR}$ (bpm) & \multicolumn{2}{|c|}{ Subjective/RPE } \\
\hline $\begin{array}{c}/ 14 \\
\text { Session } 1\end{array}$ & $\begin{array}{l}141 / 83 \mathrm{mmHg} \\
78 \mathrm{bpm}\end{array}$ & $\begin{array}{l}114 / 68 \mathrm{~mm} \mathrm{Hg} \\
86 \mathrm{bpm}\end{array}$ & $\begin{array}{l}\text { Punches } 30 " \text { " } 4 \\
\text { Butt kicks } 30 " \text { x } 4 \\
\text { *Reverse flies } 30 " \text { x } 4 \\
\text { "Skiers } 30 \text { " x } 4\end{array}$ & $\begin{array}{l}90 \\
97 \\
102 \\
105\end{array}$ & \multicolumn{2}{|c|}{$\begin{array}{c}\text { Pretty good } \\
\text { OK } \\
\text { Ok, starting to get } \\
\text { HA } \\
\text { Uncomfortable } \\
\end{array}$} \\
\hline $\begin{array}{c}3 / 17 \\
\text { Session } 2\end{array}$ & $\begin{array}{l}117 / 74 \mathrm{mmHg} \\
64 \mathrm{bpm}\end{array}$ & $\begin{array}{l}124 / 80 \mathrm{mmHg} \\
96 \mathrm{bpm}\end{array}$ & $\begin{array}{l}\text { Punches } 45 \text { " x } 4 \\
\text { Butt kicks } 45 \text { " x } 4 \\
\text { "Reverse flies } 45 \text { " x } 4 \\
\text { *Skiers } 45 \text { " x } 4 \\
\text { *Jumping jacks } 45 \text { " x } 4 \\
\end{array}$ & $\begin{array}{l}106 \\
114 \\
114 \\
119 \\
116 \\
\end{array}$ & \multicolumn{2}{|c|}{$\begin{array}{l}\text { Fine } \\
\text { Good } \\
\text { Good } \\
\text { Good } \\
\text { Good }\end{array}$} \\
\hline $\begin{array}{c}/ 19 \\
\text { Session } 3\end{array}$ & $\begin{array}{l}113 / 70 \mathrm{mmHg} \\
87 \mathrm{bpm}\end{array}$ & $\begin{array}{l}142 / 68 \mathrm{mmHg} \\
99 \mathrm{bpm}\end{array}$ & $\begin{array}{l}\text { Jump rope } 1 \min \times 4 \\
\text { Side to side jumps } 1 \text { min } \times 4 \\
{ }^{*} \text { Skiers } 1 \min \times 4 \\
\text { *Jumping jacks } 1 \min \times 4\end{array}$ & $\begin{array}{l}96 \\
107 \\
121 \\
123\end{array}$ & \multicolumn{2}{|c|}{$\begin{array}{l}13 \text { (RPE) } \\
12 \text { (RPE) } \\
15 \text { (RPE) } \\
13 \text { (RPE) }\end{array}$} \\
\hline $\begin{array}{c}3 / 24 \\
\text { Session } 4\end{array}$ & $\begin{array}{l}112 / 72 \mathrm{mmHg} \\
92 \mathrm{bpm}\end{array}$ & \multicolumn{5}{|c|}{$\begin{array}{l}\text { Reassessment of 6MWT: The decision was made to reassess the patient's } 6 \text {-minute walk test time and reported symptoms } \\
\text { before her aquatic session. The patient performed } 3 \text { minutes of walking and then had a fainting spell. The patient reported } \\
\text { that she did not take her nuun tablets today and also did not wear her compression stockings to school. Her pulse was } \\
\text { assessed in supine }(75 \mathrm{bpm}) \text {, sitting on floor ( } 89 \mathrm{bpm}) \text {, and sitting in chair }(81 \mathrm{bpm}) \text {. There was no treatment following } \\
\text { this incident. }\end{array}$} \\
\hline $\begin{array}{c}4 / 7 \\
\text { Session } 5\end{array}$ & $\begin{array}{l}127 / 78 \mathrm{mmHg} \\
96 \mathrm{bpm}\end{array}$ & $\begin{array}{l}149 / 82 \mathrm{mmHg} \\
96 \mathrm{bpm}\end{array}$ & $\begin{array}{l}\text { Punches } 1 \min \times 4 \\
\text { *Reverse flies } 1 \text { min } \times 4 \\
\text { *Jumping jacks } 1 \text { min } \times 4 \\
\text { *Skiers } 1 \text { min } \times 4\end{array}$ & & $\begin{array}{c}01 \\
110 \\
122 \\
115\end{array}$ & $\begin{array}{l}12 \\
12 \\
14 \\
11\end{array}$ \\
\hline $\begin{array}{c}4 / 9 \\
\text { Session } 6\end{array}$ & $\begin{array}{l}117 / 75 \mathrm{~mm} \mathrm{Hg} \\
95 \mathrm{bpm}\end{array}$ & $\begin{array}{l}122 / 70 \mathrm{~mm} \mathrm{Hg} \\
100 \mathrm{bpm}\end{array}$ & $\begin{array}{l}\text { *Punches with helmets } 1 \text { min } \times 4 \\
\text { *Skiers } 1 \text { min } \times 4 \\
\text { *Jumping jacks } 1 \text { min } \times 4 \\
\text { Run in place } 1 \text { min } \times 4\end{array}$ & & $\begin{array}{l}110 \\
122 \\
116 \\
121\end{array}$ & $\begin{array}{l}15 \\
16 \\
14 \\
12\end{array}$ \\
\hline $\begin{array}{c}4 / 21 \\
\text { Session } 7\end{array}$ & $\begin{array}{l}125 / 65 \mathrm{~mm} \mathrm{Hg} \\
79 \mathrm{bpm}\end{array}$ & $\begin{array}{l}114 / 61 \mathrm{~mm} \mathrm{Hg} \\
99 \mathrm{bpm}\end{array}$ & $\begin{array}{l}\text { *Punches with helmets } 1 \text { min } \times 4 \\
\text { *Skiers } 1 \text { min } \times 4 \\
\text { *Jumping jacks } 1 \text { min } \times 4 \\
\text { *Reverse flies } 1 \text { min } \times 4\end{array}$ & & $\begin{array}{l}114 \\
122 \\
114 \\
110 \\
\end{array}$ & $\begin{array}{l}12 \\
13 \\
11 \\
10 \\
\end{array}$ \\
\hline $\begin{array}{c}4 / 23 \\
\text { Session } \\
8^{\dagger}\end{array}$ & $\begin{array}{l}113 / 84 \mathrm{mmHg} \\
85 \mathrm{bpm}\end{array}$ & $\begin{array}{l}118 / 70 \mathrm{mmHg} \\
105 \mathrm{bpm}\end{array}$ & $\begin{array}{l}\text { *Reverse flies } 1 \min \times 4 \\
\text { *Jumping jacks } 1 \min \times 4 \\
\text { Run in place } 1 \min \times 4 \\
{ }^{*} \text { Double knee tuck jump } 1 \min \times 4\end{array}$ & & $\begin{array}{l}100 \\
109 \\
107 \\
107\end{array}$ & $\begin{array}{l}13 \\
15 \\
13 \\
17\end{array}$ \\
\hline $\begin{array}{c}4 / 25 \\
\text { Session } \\
9^{\dagger}\end{array}$ & $\begin{array}{l}108 / 72 \mathrm{~mm} \mathrm{Hg} \\
113 \mathrm{bpm}\end{array}$ & $\begin{array}{l}124 / 62 \mathrm{~mm} \mathrm{Hg} \\
100 \mathrm{bpm}\end{array}$ & $\begin{array}{l}\text { Reverse flies resistance paddles } 1 \text { min } \times 4 \\
\text { *Jumping jack } 1 \text { min } \times 4 \\
\text { Run in place ankle buoyancy cuffs } 1 \text { min } \times 4 \\
{ }^{*} \text { Double knee tuck jumps } 1 \text { min } \times 4\end{array}$ & & $\begin{array}{l}113 \\
113 \\
103 \\
108\end{array}$ & $\begin{array}{l}13 \\
15 \\
12 \\
16 \\
\end{array}$ \\
\hline $\begin{array}{c}5 / 12 \\
\text { Session } \\
10^{\dagger}\end{array}$ & $\begin{array}{l}105 / 53 \mathrm{~mm} \mathrm{Hg} \\
87 \mathrm{bpm}\end{array}$ & $\begin{array}{l}111 / 68 \mathrm{mmHg} \\
97 \mathrm{bpm}\end{array}$ & $\begin{array}{l}\text { *Punches with helmets } 1 \text { min } \times 4 \\
\text { *Jumping jacks } 1 \text { min } \times 4 \\
\text { *Double knee tuck noodle } 1 \text { min } \times 4 \\
\text { Recumbent bike noodle } 1 \text { min } \times 4\end{array}$ & & $\begin{array}{l}93 \\
93 \\
97 \\
103\end{array}$ & $\begin{array}{l}12 \\
13 \\
15 \\
14 \\
\end{array}$ \\
\hline $\begin{array}{c}5 / 14 \\
\text { Session } \\
11^{\dagger}\end{array}$ & $\begin{array}{l}122 / 68 \mathrm{mmHg} \\
89 \mathrm{bpm}\end{array}$ & $\begin{array}{l}107 / 79 \mathrm{~mm} \mathrm{Hg} \\
101 \mathrm{bpm}\end{array}$ & $\begin{array}{l}\text { *Jumping jacks buoyancy cuffs } 1 \text { min } \times 4 \\
\text { *Double knee tuck jumps } 1 \text { min } \times 4 \\
\text { Recumbent scissor twist noodle } 1 \text { min } \times 4 \\
\text { *Skiers } 1 \mathrm{~min} \times 4\end{array}$ & & $\begin{array}{c}103 \\
92 \\
105 \\
106\end{array}$ & $\begin{array}{l}13 \\
12 \\
15 \\
14 \\
\end{array}$ \\
\hline
\end{tabular}

${ }^{*}$ Denotes exercises that appeared in 3 or more sessions and that the patient showed a decreased exercising heart rate and/or RPE after performing.

† Denotes exercises completed in deep water with Aquajogger vest. 
Prior to and following each physical therapy session, the patient's blood pressure and pulse were recorded, using an auto-inflate blood pressure cuff. Additionally, a subjective report included how she was feeling before, during, immediately after, and 5 minutes after her exercises. It also included any flare up of symptoms between sessions and her report of how she felt when she went home after her sessions. Table 1 details the patient's subjective report, exercise program, and physiologic monitoring for each physical therapy session.

\section{OUTCOMES}

Over the course of physical therapy, the patient demonstrated a progressive increase in exercise tolerance. She was able to transition from 30 seconds of exercise with a minute break to one minute of exercise with a 30 -second break. While exercises were varied among sessions, the patient completed several of the exercises during multiple visits. These exercises are identified with an asterisk $\left(^{*}\right)$ in Table 1. The patient's lower HR and RPE scores over time, with progressive advancement of the intensity and duration of the exercises, demonstrate her increasing tolerance to those exercises.

At her last visit, the patient repeated the WHOQOL-BREF questionnaire. These results, as well her initial WHOQOL-BREF scores are summarized in Table 2. In her final WHOQOL-BREF questionnaire, the patient showed increases in the following domains: quality of life and health and social relationships. However, the patient's scoring on the WHOQOL-BREF questionnaire declined in the following categories: physical health, psychological health, and environment. The patient was scheduled for continued physical therapy sessions, but cancelled or no-showed for all subsequent appointments, so a formal re-evaluation was not completed.

Table 2: WHOQOL-BREF Quality of Life Scores at Evaluation and Discharge

\begin{tabular}{|c|c|c|}
\hline Domain & Initial & Last visit \\
\hline Quality of life and health & 37.5 & 50 \\
\hline Physical health & 42.9 & 39.3 \\
\hline Psychological health & 45.8 & 25 \\
\hline Social relationships & 25 & 33.3 \\
\hline Environment & 96.4 & 89.2 \\
\hline
\end{tabular}

Over the last few visits, the patient reported significant gains in her functional abilities and her participation as a student. She discontinued the use of the wheelchair and was able to attain the functional goals she had set at the onset of physical therapy: to walk from class to class (distances up to $500 \mathrm{~m}$ in 7-minute passing period), stand for 45 minutes at her choir concert, attend her senior prom (tolerated 4 hours of standing/walking/dancing with seated rest breaks), and walk across stage to receive her diploma at her high school graduation. The patient reported that she had not experienced a fainting spell in over a month, nor any abdominal pain in about three weeks.

\section{DISCUSSION}

Physical therapy treatment options for individuals with POTS have not been well documented. The purpose of this case report is to describe the use of interval training in an aquatic environment to decrease the symptoms of POTS.

The use of aquatic therapy for this patient was made collaboratively by the physical therapist and the physician. Taken into account were the persistence of the patient's symptoms despite pharmaceutical intervention, the positive effects of aquatic therapy on challenged cardiovascular systems in the literature, and the patient's needs and values. ${ }^{25}$ The principle of hydrostatic pressure and its effect on the cardiovascular system was the primary factor in choosing aquatic exercise. ${ }^{21-23}$ Water pressure is directly proportional to the immersion depth, exerting a force of $22.4 \mathrm{~mm} \mathrm{Hg} / \mathrm{foot}$ of water depth. A human body immersed at a depth of 48 inches is subjected to a force equal to $88.9 \mathrm{~mm} \mathrm{Hg} \cdot{ }^{36}$ Because this pressure is higher than normal diastolic pressure, the return of blood to the heart is facilitated. The effects of hydrostatic pressure on the body begin immediately upon submersion and include cephalad displacement of blood and the diaphragm, chest wall compression, increased right atrial pressure, and increased pleural surface pressure. ${ }^{36}$ Ultimately, the efficiency of the cardiovascular system is enhanced, which may explain the patient's ability to tolerate not only standing in water, but exercising as well. Prior to the initiation of aquatic exercise, the patient was deconditioned and unable to tolerate more than 10 minutes of standing on land. In the water, the patient was not only able to stand but also participate in a moderate to vigorous (Borg RPE 12 to 16) interval training program for 30 minutes. The patient was very satisfied with her outcomes and symptom reduction. She attributed the decrease in her symptoms to the aquatic therapy program really helped to alleviate her symptoms so that she could return back to her previous lifestyle. 
The outcomes in this case report are consistent with changes in cardiovascular function following 8 to 12 weeks of aquatic exercise in recent studies with different patient populations. ${ }^{37}$ Alkatan et al studied 48 sedentary adults with osteoarthritis, randomly assigned to a land-based or an aquatic-based exercise group. ${ }^{37}$ Participants underwent a 12-week exercise program (20 to 30 minutes/day, 3x/week) starting at an exercise intensity of 40 to $50 \%$ heart rate reserve (HRR) and building to an intensity of 60 to $70 \%$ HRR. Following the program, the participants in both groups demonstrated significant reduction in arterial stiffness ( $p<.05)$ as well as a decrease in central systolic and peripheral pulses. The aquatic exercise group showed improvement in endothelial dependent vasodilation, measured by brachial flow-mediated dilation. This study suggests that an aquatic therapy program can alter vascular pliability and function. This improved vascular function may explain the patient's ability to tolerate exercise in water in this case study.

A randomized controlled study compared the effects of aquatic versus land exercises on endurance in individuals with COPD. ${ }^{38}$ Participants were randomly allocated to one of three intervention groups: land-based exercise, aquatic exercise, and a control group (no exercise). McNamara et al concluded that water-based exercise training was significantly more effective than landbased exercise training or no training (control) for improving peak and endurance exercise capacity and improving aspects of quality of life in patients with COPD and physical co-morbidities. ${ }^{38}$ Although these studies did not examine the effects of aquatic exercise in patient with POTS, they do examine a patient population with cardiovascular dysfunction.

Despite the patient's subjective report of meeting all of the functional goals that she set for physical therapy and overall improvement in quality of life as measured by the WHOQOL-BREF, her scores in the physical, psychological, and environmental categories of the WHOQOL-BREF questionnaire actually declined from the initial evaluation to her final therapy session (see Table 2). There are several factors which could have influenced these scores. When completing the questionnaire, the patient is instructed to consider "the last two weeks" when answering questions. The patient may have had a recent day with more symptoms that influenced her ratings. Over the course of therapy, the patient's expectation may have changed significantly.

Prior to beginning therapy, the patient was severely limited in her participation and activities for a year and she may have been resigned to that fact. Throughout the course of therapy, as her activity limitations and participation restrictions declined, the patient may have shifted her expectations regarding her participation in school and leisure activities. The patient was also approaching a major life milestone, graduating from high school and starting her college education. This too may have resulted in increased anxiety about how POTS could limit her in fully participate in the college experience. These findings suggest that it may be important for patients with POTS to also seek out psychological treatment in addition to exercise.

The effects of the medications and compression stockings in this case report should not be discounted. The patient was taking cardio-selective beta blockers (Bystolic/Nebivolol) to decrease the patient's blood pressure through vasodilation. This may have resulted in decreased heart rate and thus her rate of perceived exertion. Unlike many other beta-blockers that decrease an individual's exercise capacity, Nebivolol has been shown to have no effect on exercise capacity in a healthy population and an increased exercise capacity in patients with heart failure ${ }^{39}$ The patients' medication may have contributed to her tolerance of the aquatic exercise training. However, the patient had been taking the medication and using the stockings for several months without a significant change in her symptoms. Given that the only modification to the course of treatment was the addition of aquatic exercise, we may be able to attribute some of the positive changes in her activity tolerance to this exercise modality. We cannot conclusively say that her functional gains were a direct result of the aquatic therapy.

During the 10-week course of physical therapy, the patient was unable to attend several treatment sessions as a result of a combination of symptoms. Often, patients with POTS simply cannot get out of bed to leave the house. Ironically, the reason for needing the physical therapy often made attending physical therapy sessions difficult. Because of this, the number of physical therapy sessions was limited and the intervals between sessions were also inconsistent. Despite these inconsistencies, the patient was able to improve her activity tolerance and meet the functional goals set for physical therapy: walking through school, attending graduation, performing in her choir concert, and attending the prom.

This case report demonstrated that aquatic exercise had a positive effect on this patient's ability to participate in school and leisure activities. Improvements in exercise tolerance, demonstrated by lower heart rates and RPE scores as the sessions progressed, were reported. The patient also reported a decrease of her symptoms including no recent fainting spells, migraines or body aches. This case report suggests that aquatic therapy may be an effective intervention for relieving the symptoms of POTS. Further research, including randomized controlled trials, is warranted to better understand how to effectively manage patients with POTS.

(c) The Internet Journal of Allied Health Sciences and Practice, 2017 


\section{REFERENCES}

1. Schondorf R, Low P. Idiopathic postural orthostatic tachycardia syndrome: an attenuated form of acute pandysautonomia? Neurology. 1993;43(1):132-7. [PMID: 8423877]

2. Antiel RM, Risma JM, Grothe RM, Brands CK, Fischer PR. Orthostatic intolerance and gastrointestinal motility in adolescenets with nausea and abdominal pain. J Pediatr Gastroenterol Nutr. 2008;46(3):285-8. [PMID: 18376245]

3. Agarwal AK, Garg R, Ritch A, Sarkar P. Postural orthostatic tachycardia syndrome. Postgrad Med J. 2007;83(981):478-80. [PMID: 17621618]

4. Benarroch EE. Postural tachycardia syndrome: a hetergeneous and multifactorial disorder. Mayo Clin Proc. 2012;87(12):1214-25. [PMID: 23122672]

5. Carew S, Connor MO, Cooke J, Conway R, Sheehy C, Costelloe A, et al. A review of postural orthostatic tachycardia syndrome. Europace. 2009;11(1):18-25. [PMID: 19088364]

6. Abed H, Ball P, Wang LX. Diagnosis and management of postural orthostatic tachycardia syndrome: a brief review. $J$ Geriatr Cardiol. 2012;9(1):61-7. [PMID: 22783324]

7. Stewart JM. Common syndromes of irthostatic intolerance. Pediatrics. 2013;131(5):968-80. [PMID: 23569093]

8. Kizilbash SJ, Ahrens SP, Bruce BK Chelimsky G, Driscol SW, Harbeck-Weber C, et al. Adolescent fatigue, POTS, and recovery: a guide for clinicians. Curr Probl Pediatr Adolesc Health Care. 2014;44(5):108-33. [PMID: 24819031]

9. Jordan J. Effect of water drinking on sympathetic nervous activity and blood pressure. Curr Hypertens Rep. 2005;7(1):1720. [PMID: 15683582]

10. Mathias $C$, Young T. Water drinking in the management of orthostatic intolerance due to orthostatic hypotension, vasovagal syncope, and the postural tachycardia syndrome. Eur J Neurol. 2004;11:613-9. [PMID: 15379740]

11. Benrud-Larson L, Dewar M, Sandroni P, Rummans T, Haythornthwaite J, Low P. Quality of life in patients with postural tachycardia syndrome. Mayo Clinic Proceedings 2002;77:531-7. [PMID: 12059122]

12. Anderson JW, Lambert EA, Sari Cl, Dawood T, Esler MD, Vaddadi G, et al. Cognitive function, health-related quality of life, and symptoms of depression and anxiety sensitivity are impaired in patients with postural orthostatic tachycardia syndrome (POTS). Front Physiol. 2014;5(230):1-9. [PMID: 25009504]

13. Grubb BP. Postural tachycardia syndrome. Circulation. 2008;117(21):2814-7. [PMID: 27631244]

14. Skinner J, Driscoll S, Porter C. Orthostatic heart rate and blood pressure and heart rate in adolescents: reference ranges. J Child Neurol. 2010;25(10):1210-5. [PMID: 20197269]

15. Singer W, Sletten D, Opfer Gerkhing T, Brands C, Fischer P, Low P. Postural tachycardia in children and adolescents: what is normal? J Pediatr. 2012;160(2):222-6. [PMID: 21996154]

16. Crnosija L, Skoric MK, Adamec I, Mismas A, Viletic V, Sprljan-Alfirev R, et al. ID 5 - Head-up tilt table test in differentiating neuropathic from hyperadrenergic type of postural orthostatic tachycardia syndrome (POTS). Clin Neurophysiol. 2016;127(3):e66. [PMID: 26386646]

17. Fu Q, Levine BD. Exercise in the postural orthostatic tachycardia syndrome. Auton Neurosci. 2015;188:86-9. [PMID: 25487551]

18. Nwazue VC, Raj SR. Cofounders of vasovagal syncope: postural tachycardia syndrome. Cardiol Clin. 2013 February;31(1):101-9. [PMID: 23217691]

19. Kisner C, Colby L. Therapeutic Exercise: Foundations and Techniques, 6e. Philadelphia, PA: F.A. Davis Company; 2012:290-311.

20. Denning WM, Bressel E, Dolny D, Bressel M, Seeley MK. A review of biophysical differences between aquatic and landbased exercise. Int J Aquat Res Educ. 2012;6(1):46-67.

21. Cameron MH. Physical Agents in Rehabilitation: From Research to Practice, 4e. St. Louis, MO: Elsevier Saunders; 2013:322-56.

22. Risch WD, Koubenec HJ, Beckmann U, Lange S, Gauer OH. The effect of graded immersion on heart volume, central venous pressure, pulmonary blood distribution and heart rate in man. Pfleugers Arch. 1978;374:115-8. [PMID: 149298]

23. Haffor AA, Mohler JG, Harrison AAC. Effects of water immersion on cardiac output of lean and fat male subjects at rest and during exercise. Aveiat Space Environ Med. 1991;62:123-7. [PMID: 1900415]

24. Vina J, Sanchis-Gomar F, Martinez-Bello V, Gomez-Cabrera MC. Exercise acts as a drug; the pharmacological benefits of exercise. Br J Pharmacol. 2012;167:1-12. [PMID: 22486393]

25. Meyer K, Leblanc M-C. Aquatic therapies in patients with compromised left ventricular function and heart failure. Clin Invest Med. 2008;31(2):E90-E97. [PMID: 18377766]

26. Cuthbert S, Goodheart G. On the reliability and validity of manual muscle testing: a literature review. Chiropr Osteopat. 2007;15(4). [PMID: 17341308]

27. Richter R, Reinking MF. How does evidence on the diagnostic accuracy of the vertebral artery test influence teaching of the test in a professional physical therapist education program? Phys Ther. 2005;85(6):589-99. [PMID: 15921479]

(C) The Internet Journal of Allied Health Sciences and Practice, 2017 
28. Naschitz J, Rosner I. Orthostatic hypotension: framework of the syndrome. Postgrad Med J. 2007;83(983):568-74. [PMID: 17823222]

29. Freeman R, Wieling W, Axelrod F, Benditt DG, Benarroch E, Biaggionni I, et al. Consensus statement on the definition of orthostatic hypotension, neurally mediated syncope and the postural tachycardia syndrome. Auton Neurosci. 2011;161:468. [PMID: 21393070]

30. Geiger R, Strasak A, Treml B, Gasser K, Kleinsasser A, Fischer V, et al. Six-minute walk test in children and adolescents. J Pediatr. 2007;150(4):395-9. [PMID: 17382117]

31. Li A, Yin J, Yu C, Tsang T, So HK, Wong E, et al. The six-minute walk test in healthy children: reliability and validity. Eur Respir J. 2005;25(6):1057-60. [PMID: 15929962]

32. Larsson U, Reynisdottir S. The six-minute walk test in outpatients with obesity: reproducibility and known group validity. Physiother Res Int. 2008;13(2):84-93. [PMID: 18446882]

33. Skevington S, Dehner S, Gillison F, McGrath E, Lovell C. How appropriate is the WHOQOL-BREF for assessing the quality of life of adolescents? Psychol Health. 2014;29(3):297-317. [PMID: 24192254]

34. Losa-Iglesias M, Becerro-de-Bengoa-Vallejo R, Becerro-de-Bengoa-Losa K. Reliability and concurrent validity of a peripheral pulse oximeter and health-app system for the quantification of heart rate in healthy adults. Health Informatics $J$ July 18, 2014. [PMID: 25038201]

35. Scherr J, Wolfarth B, Christle J, Pressler A, Wagenpfeil S, Halle M. Associations between Borg's rating of perceived exertion and physiological measures of exercise intensity. Eur J Appl Physiol. 2013;113(1):147-55. [PMID: 22615009]

36. Becker B. Aquatic therapy: scientific foundations and clinical rehabilitation applications. Phys Med Rehabil. 2009;1:859-72. [PMID: 19769921]

37. Alkatan M, Baker JR, Machin DR, Akkari AS, Park W, Tanaka $\mathrm{H}$, et al. Improved function and reduced pain after swimming and cycling training in patients with osteoarthritis. J Rheumatol. 2016:43(3):667-72. [PMID: 26773104]

38. McNamara RJ, McKeough ZJ, McKenzie DK, Alison JA. Water-based exercise in COPD with physical comorbidities: a randomised controlled trial. Eur Respir J. 2013;41:1284-91. [PMID: 22997217]

39. Ladage D, Schwinger R, Brixius K. Cardio-selective beta-blocker: pharmacological evidence and their influence on exercise capacity. Cardiovasc Ther. 2013;31(2):76-83. [PMID: 22279967]

Appendix A: WHOQOL-BREF (acquired from the University of Washington: depts.washington.edu)

Overall Quality of Life and General Health 


\begin{tabular}{|l|c|c|c|c|c|}
\hline & Very poor & Poor & Neither poor or good & Good & Very Good \\
\hline $\begin{array}{l}\text { How would you rate } \\
\text { your quality of life? }\end{array}$ & 1 & 2 & 3 & 4 & 5 \\
\hline & $\begin{array}{c}\text { Very } \\
\text { dissatisfied }\end{array}$ & Dissatisfied & $\begin{array}{c}\text { Neither satisfied or } \\
\text { dissatisfied }\end{array}$ & Satisfied & Very satisfied \\
\hline $\begin{array}{l}\text { How satisfied are } \\
\text { you with your } \\
\text { health? }\end{array}$ & 1 & 2 & 3 & 4 & 5 \\
\hline
\end{tabular}

The following questions ask about how much you have experienced certain things in the last two weeks.

\begin{tabular}{|l|c|c|c|c|c|}
\hline & Not at all & A little & $\begin{array}{c}\text { A moderate } \\
\text { amount }\end{array}$ & Very much & $\begin{array}{c}\text { An extreme } \\
\text { amount }\end{array}$ \\
\hline $\begin{array}{l}\text { To what extent do you feel that physical pain } \\
\text { prevents you from doing anything you need to } \\
\text { do?* Domain 1- Physical health }\end{array}$ & 1 & 2 & 3 & 4 & 5 \\
\hline $\begin{array}{l}\text { How much do you need any medical treatment to } \\
\text { function in your daily life? Domain 1- Physical } \\
\text { health }\end{array}$ & 1 & 2 & 3 & 4 & 5 \\
\hline $\begin{array}{l}\text { How much do you enjoy life? Domain 2- } \\
\text { Psychological }\end{array}$ & 1 & 2 & 3 & 4 & 5 \\
\hline $\begin{array}{l}\text { To what extent do you feel life to be meaningful? } \\
\text { Domain 2- Psychological }\end{array}$ & 1 & 2 & 3 & 4 & 5 \\
\hline $\begin{array}{l}\text { How well are you able to concentrate? Domain } \\
\text { 2-Psychological }\end{array}$ & 1 & 2 & 3 & 4 & 5 \\
\hline $\begin{array}{l}\text { How safe do you feel in your daily life? Domain } \\
\text { 4-Environment }\end{array}$ & 1 & 2 & 3 & 4 & 5 \\
\hline $\begin{array}{l}\text { How healthy is your physical environment? } \\
\text { Domain 4-Environment }\end{array}$ & 1 & 2 & 3 & 4 & 5 \\
\hline
\end{tabular}

The following questions ask about how completely you experience or were able to do certain things in the last two weeks.

\begin{tabular}{|l|c|c|c|c|c|}
\hline & $\begin{array}{c}\text { Not at } \\
\text { all }\end{array}$ & A little & Moderately & Mostly & Completely \\
\hline $\begin{array}{l}\text { Do you have enough energy for everyday life? } \\
\text { Domain 1- Physical health }\end{array}$ & 1 & 2 & 3 & 4 & 5 \\
\hline $\begin{array}{l}\text { Are you able to accept your bodily } \\
\text { appearance? Domain 2-Psychological }\end{array}$ & 1 & 2 & 3 & 4 & 5 \\
\hline $\begin{array}{l}\text { Have you enough money to meet your needs? } \\
\text { Domain 4- Environment }\end{array}$ & 1 & 2 & 3 & 4 & 5 \\
\hline $\begin{array}{l}\text { How available to you is the information you } \\
\text { need in your day-to-day life? Domain 4- } \\
\text { Environment }\end{array}$ & 1 & 2 & 3 & 4 & 5 \\
\hline $\begin{array}{l}\text { To what extent do you have the opportunity for } \\
\text { leisure activities? Domain 4- Environment }\end{array}$ & 1 & 2 & 3 & 4 & 5 \\
\hline & $\begin{array}{l}\text { Very } \\
\text { poor }\end{array}$ & Poor & $\begin{array}{c}\text { Neither poor } \\
\text { or well }\end{array}$ & Well & Very well \\
\hline $\begin{array}{l}\text { How well are you able to get around? Domain } \\
\text { 1-Physical health }\end{array}$ & 1 & 2 & 3 & 4 & 5 \\
\hline
\end{tabular}

The following questions ask you to say how good or satisfied you have felt about various aspects of your life over the last two weeks.

\begin{tabular}{|l|c|c|c|c|c|}
\hline & $\begin{array}{c}\text { Very } \\
\text { dissatisfied }\end{array}$ & Dissatisfied & $\begin{array}{c}\text { Neither satisfied } \\
\text { or dissatisfied }\end{array}$ & Satisfied & $\begin{array}{c}\text { Very } \\
\text { satisfied }\end{array}$ \\
\hline
\end{tabular}




\begin{tabular}{|c|c|c|c|c|c|}
\hline $\begin{array}{l}\text { How satisfied are you with your } \\
\text { sleep? Domain 1- Physical } \\
\text { health }\end{array}$ & 1 & 2 & 3 & 4 & 5 \\
\hline $\begin{array}{l}\text { How satisfied are you with your } \\
\text { ability to perform your daily } \\
\text { living activities? Domain 1- } \\
\text { Physical health }\end{array}$ & 1 & 2 & 3 & 4 & 5 \\
\hline $\begin{array}{l}\text { How satisfied are you with your } \\
\text { capacity to work? Domain 1- } \\
\text { Physical health }\end{array}$ & 1 & 2 & 3 & 4 & 5 \\
\hline $\begin{array}{l}\text { How satisfied are you with } \\
\text { yourself? Domain 2- } \\
\text { Psychological }\end{array}$ & 1 & 2 & 3 & 4 & 5 \\
\hline $\begin{array}{l}\text { How satisfied are you with your } \\
\text { personal relationships? Domain } \\
\text { 3- Social relationships }\end{array}$ & 1 & 2 & 3 & 4 & 5 \\
\hline $\begin{array}{l}\text { How satisfied are you with your } \\
\text { sex life? Domain 3-Social } \\
\text { relationships }\end{array}$ & 1 & 2 & 3 & 4 & 5 \\
\hline $\begin{array}{l}\text { How satisfied are you from the } \\
\text { support you get from your } \\
\text { friends? Domain 3- Social } \\
\text { relationships }\end{array}$ & 1 & 2 & 3 & 4 & 5 \\
\hline $\begin{array}{l}\text { How satisfied are you with the } \\
\text { conditions of your living place? } \\
\text { Domain 4- Environment }\end{array}$ & 1 & 2 & 3 & 4 & 5 \\
\hline $\begin{array}{l}\text { How satisfied are you with your } \\
\text { access to health services? } \\
\text { Domain 4-Environment }\end{array}$ & 1 & 2 & 3 & 4 & 5 \\
\hline \multirow[t]{2}{*}{$\begin{array}{l}\text { How satisfied are you with your } \\
\text { mode of transportation? } \\
\text { Domain 4-Environment }\end{array}$} & 1 & 2 & 3 & 4 & 5 \\
\hline & Never & Seldom & Quite often & Very Often & Always \\
\hline $\begin{array}{l}\text { How often do you have negative } \\
\text { feelings, such as blue mood, } \\
\text { despair, anxiety or depression?* } \\
\text { Domain 2-Psychological }\end{array}$ & 1 & 2 & 3 & 4 & 5 \\
\hline
\end{tabular}

\section{Scoring Instructions:}

Sum up the scores of each domain (1-4) to achieve a raw score. There are 3 items that will be scored as a negative when summing up the domain; these items have been marked with an asterisk.

\begin{tabular}{|l|l|}
\hline Domains & Possible Range of Raw Scores \\
\hline Overall Health and QOL & $2-10$ points \\
\hline Domain 1: Physical Health & $7-35$ points \\
\hline Domain 2: Psychological & $6-30$ points \\
\hline Domain 3: Social Relationships & $3-15$ points \\
\hline Domain 4: Environment & $8-40$ points \\
\hline
\end{tabular}

If an item is left blank its score can be computed as the average of the remaining items in its domain. If two or more items from a particular domain are left blank then that domain cannot be scored.

Raw score to transformed score

Transformed score (per domain) $=$ (actual raw score- lowest possible raw score) $/$ (range of raw scores) 